\section{A Diferença, qual diferença? \\ O Mesmo e o Outro à luz das artes cênicas na África}

\author{
La différence, quelle différence? Le Même et l'Autre \\ à la lumière des arts de la scène en Afrique
}

Christine Douxami ${ }^{1}$

RESUMO

O presente artigo aborda o tema da diferença numa perspectiva de disseminação a partir da África. A pesquisa considera o contexto atual da arte contemporânea na África e na diáspora no âmbito das artes cênicas, tendo em vista os diferentes paradigmas desenvolvidos no decorrer do movimento da negritude e do pan-africanismo. Atualmente, um teatro extremamente político está em ebulição e busca se posicionar frente à obra dos fundadores do teatro na época das independências no continente. Entretanto, partimos de uma mesma falta de lucidez tanto no Norte como no Sul: nossa falta de habilidade face à Diferença e a necessidade de uma reflexão política bem como sensivel. Nós partimos de uma mesma busca a respeito do Mesmo e do Diferente, que transcenda a presença de pigmentos ou de cromossomos $\mathrm{X}, \mathrm{Y}, 21,10$ ou 15. O ponto de partida desta pesquisa pressupõe que sejamos todos Diferentes e que somente varie o referencial escolhido como determinante da Diferença. Em seguida, considera-se o empenho do artista-pesquisador e seu parecer no contexto do estudo do Outro.

Palavras-chave: Diferença. Racismo. África. Artes cênicas. Pesquisaação. Pesquisa-criação.
1.

Institut des Mondes Africains (EHESS-CNRS-IRD) e Université de Franche-Comté. ORCID: https://orcid.org/ 0000-0002-8465-3978 Contato:

chrisluabela@yahoo.fr Christine Douxami é pesquisadora em antropologia da arte no Institut des Mondes Africains (IMAF-EHESS-CNRS) e professora adjunta de artes cênicas na Université de Franche-Comté. Seu trabalho, que mistura teatro e antropologia, visa as formas de artes engajadas ligadas à negritude e ao pan-africanismo, especialmente na África e no Brasil, através de diferentes festivais e diversas representações cênicas tanto em lugares oficialmente dedicados à arte como na rua ou através do estudo dos patrimônios imateriais. Suas obras: Théâtres Politiques. (En) Mouvement(s) (Dir.) e Le théâtre noir brésilien, un processus militant d'affirmation de l'identité afro-brésilienne. Ela codirigiu o filme Fesman 2010, De l'Est à l'Ouest, du Nord au Sud disponível na página do Canal U na internet. 


\section{RÉSUMÉ}

L'article présenté ici envisage le thème de la différence à partir d'une perspective de décentrement depuis l'Afrique. La recherche envisagera le contexte actuel de l'Art contemporain en Afrique et dans la diaspora au sein des Arts performatifs et prendra en compte les différents paradigmes développés depuis le mouvement de la négritude au sein du panafricanisme notamment. Un théâtre éminemment politique cherchant à se positionner vis-à-vis des pères fondateurs du théâtre en Afrique depuis les indépendances est en ébullition. Nous partons d'une même inégalité au Nord comme au Sud: notre même maladresse face à la différence et notre besoin d'une même réflexion politique et sensible, d'une quête identique autour du même et du différent, qu'il passe par une présence en deçà ou en dessus de pigments ou de chromosomes $X$, Y, 21, 10 ou 15. Le point de départ de cette recherche postule que nous sommes tous différents et que seul varie le critère choisi comme déterminant cette différence. Puis nous envisagerons le positionnement et l'engagement de l'artiste-chercheur dans ce contexte d'étude de l'Autre.

Mots clé: Différence. Racisme. Afrique. Arts de la scène. Rechercheaction. Recherche-création. 
O artigo coloca em perspectiva as relações complexas entre a criação artística contemporânea na África, o mundo globalizado e a exacerbação das diferenças nos dias de hoje: como os artistas contemporâneos africanos tratam o « diferente » (no sentido amplo do termo), tanto para aqueles que vivem no continente como os que estão na diáspora seja na dança, no teatro, nas artes plásticas, na fotografia, no cinema, na música, na literatura ou nas artes digitais? Para além das antigas relações colonizador-colonizado que ainda sustentam as concepções do que é arte ou não, como a distinção do que seria « arte » ou « simples objeto etnográfico », os artistas do continente africano se perguntam: em que seriam tão « diferentes » e « exóticos », a ponto que suas realizações artísticas traduzam visivelmente esta Diferença? Por que suas identidades artísticas são essencializadas mesmo que suas escolhas artísticas não reflitam obrigatoriamente seu pertencimento ao continente?

Faz-se também a pergunta do que é « arte », ou não, em um mundo mercantil, tanto no nível do mercado de arte contemporâneo, quanto das artes da cena contemporânea. O teatro e as artes coreográficas da África sofrem uma negação de sua essência como obra de arte até os dias de hoje, tanto pelo público nacional como internacional. Essa negação das artes cênicas e de sua relevância artística existe mesmo quando o diretor e o coreógrafo provêm de um ambiente artístico profissional. Deveriam todos ser « autênticos » e apresentar um « pré-teatro » ou dança dita « africana »? Esta pesquisa se baseia em diversas cooperações desde 2007 em Burkina Faso (Festival Internacional de Marionetes-FITMO e Festival Les Récréâtrales), no Senegal e através de intervenções regulares sobre este tema no seminário Supports et Circulation des Savoirs et des Arts (IMAF- co-organizado pela autora desde 2006).

Mesmo que todo conflito na África fosse midiaticamente qualificado de « étnico », até pouco tempo, e que a compreensão do continente passasse pelo filtro da islamização, ou não, como ir além destes conflitos étnicos ou das questões da islamização, e partir do que está subjacente, nem tanto no étnico ou no religioso, mas nessa suposta Diferença ontológica que o sujeito africano desenvolveria? É possível ler a produção cênica contemporânea do continente africano hoje de uma maneira global, partindo de uma análise histórica e antropológica de posicionamentos políticos de artistas em suas obras quanto à « negritude », ao « pan-africanismo », às diferentes formas de afirmações identitárias locais ou globais e os atuais desejos de ir além desses paradigmas.

No entanto, e é o que constitui a segunda parte de nossas reflexões, nós nos inclinamos sobre o aspecto interno do continente quanto a um questionamento da Diferença: se, como artistas do 
continente, estes são supostamente « diferentes » quando se posicionam na cena artística internacional eseas ferramentas dopan-africanismo e da negritude foram frequentemente os meios de resposta face ao Outro, então como se posicionar frenteao Mesmo? Esse Mesmo pareceexistirapenas empequenas escalas: do mesmogrupoétnico, da mesma cidade, da mesma classe social, da mesma faixa etária, da mesma língua, da mesma sexualidade, ou em alguns casos da mesma rua.

Até onde podemos então definir o Mesmo e o Outro no cotidiano em um universo sensível - como o do bebê, da criança, do adolescente e do adulto? Ser distinto do Outro é um aprendizado do bebê que se descobre diferente. Mas o que acontece quando essa diferença se volta contra nós, não como alguma coisa que nos define como um ser distinto, mas como um ser diferente, e a partir de quando essa diferença pode nos ser devolvida como sendo « anormal »? Como, de repente, a diferença lhe define enquanto « ser no mundo » e em permanência?

Ser negro no Brasil, por exemplo, pressupõe que se pegue frequentemente a escada de serviço, que não vá a certos restaurantes - porque sente-se desconfortável e não porque é proibido -, que não saia de férias com frequência, que só seja elegível a uma vaga federal desde que existem cotas, que sua taxa de mortalidade de jovens por homicídio seja três vezes mais alta que a dos jovens brancos da sua idade ${ }^{2}$. A questão do ser negro, passa frequentemente na África pelo pan-africanismo, muitas vezes ligada à negritude, não é totalmente saciada mesmo na África, e muitas vezes serve como pano de fundo, mesmo quando outros temas são considerados. Tomamos como exemplo a questão da cor na Ruanda, que pode parecer anedótica, mas outras diferenças de grupos étnicos, de classes, de sexualidade, de aparência física ligada ou não a uma deficiência podem ser estigmatizadas.

Essa diferença constante é o que significa ser « diferente » no cotidiano. Mas então o que nos faz alguém « diferente », para além das questões de cores, de classes, de cultura, de nacionalidade? Ser diferente subentende-se a existência de uma norma de dentro da sociedade, dentro das fronteiras locais, mas também em nível nacional e internacional. Ter um corpo ou um pensamento diferente talvez seja o apogeu da diferença, às vezes intitulado de « anormalidade ». A « normalidade » e sua companheira a « anormalidade » pode ser abordada sob o mesmo registro da « diferença » no sentido ontológico do termo. Se eu sou um artista negro ruandês « globalizado », em que eu deveria ser « diferente » em Bruxelas? E se eu for autista em Kigali como minha diferença vai me tornar outro?
2.

e fato, a cidadania é muitas vezes prejudicada em um país como o Brasil : como explica Larissa Borges, coordenadora do Projeto de Articulação Nacional do Plano Juventude Viva (plano federal da luta contra a mortalidade de jovens desde 2012), um jovem negro (de 15 a 29 anos) morre a cada meia hora, o que corresponde a 18 mil mortes por ano. $76,6 \%$ dos jovens mortos por homicídio em 2010 eram negros http://www.geledes.org. br, dia 10.06.2014. Existe atualmente uma campanha da Anistia Internacional chamada Jovem Negro Vivo que denuncia esse fato. 
Ser diferente é evidentemente uma questão cultural, mesmo quando consideramos a questão de uma outra distinção, a do deficiente. No Canadá, praticamente ninguém questiona o comportamento de uma criança Diferente, como o autista. Enquanto no Brasil, quando se questiona, responde-se quase sistematicamente « ah é normal! É uma criança! Somos todos diferentes ». Na França afirma-se « e daí? Ele só precisa ter cuidado! Não me interessa que seja autista ». No Senegal ou na Costa do Marfim se supõe frequentemente que a criança tem poderes potencialmente maléficos o que justifica que seja muitas vezes rejeitada à margem da sociedade.

Como expressa François Julian, pensar a alteridade « permet de sonder les parti-pris de notre propre pensée, tous ces choix enfouis que nous véhiculons comme allant de soi; bref, d'obtenir une prise oblique sur notre impensé. Car, à faire travailler ces écarts perçus entre cultures, au lieu de les laisser écraser sous le rouleau compresseur de l'uniformisation mondiale, il s'en dégage une chance nouvelle pour la raison : de pouvoir procéder, à partir de la diversité des cultures, à ce que j'appellerai l'《auto-réfléchissement » de l'humain $»^{3} 4$.

De acordo com François Julien (2012), trata-se da necessidade de um pensamento descentrado para analisar as realizações artísticas contemporâneas de hoje na África, para além do etnocentrismo inadequado que encontramos ainda nos dias de hoje nos espaços de museus ${ }^{5}$, mas também de aplicar essa postura de análise do « impensado do nosso pensamento » quanto ao diferente e ao Mesmo, tanto para os artistas africanos como para seus homólogos franceses ou brasileiros.

Logo, seja ele escritor, coreógrafo, autor, dramaturgo, fotógrafo, ator, cinegrafista, designer de luz, pensar o impensado, ou ao menos postular uma escuta sensível, é frequentemente próprio do artista. Longe de uma relação de poder Norte-Sul nós partimos de uma mesma desigualdade: nossa mesma falta de habilidade frente à Diferença e a necessidade de uma mesma reflexão política sensível, de uma busca idêntica acerca do Mesmo e do Diferente, que transcende a presença de pigmentos ou de cromossomos X, Y, 21, 10 ou 15. O ponto de partida desta pesquisa pressupõe que somos todos diferentes e que apenas varie o critério escolhido como determinante dessa diferença. Questiona-se, portanto, a noção de « diferença » através das realizações cênicas contemporâneas na África e, em menor grau, na sua diáspora.

I. Em torno de realizações pan-africanas e do questionamento da afirmação ou não da Diferença (de cor) através das artes performativas

Dorcy Rugamba é autor, diretor e ator nativo de Ruanda, que mora em Bruxelas ${ }^{6}$. Ele esteve presente em Dakar para o $3^{\circ}$ Festival
3.

JULIEN François, http:// www.fmsh.fr/fr/c/1278 (consultado dia 30/11/2015)

4 .

«permite sondar os preconceitos de nossos próprios pensamentos, todas essas escolhas enterradas que transmitimos como evidentes; em suma, para obter uma compreensão oblíqua sobre o nosso impensado. Pois, para fazer com que funcionem essas discrepâncias entre culturas, em vez de deixá-los esmagar sob o rolo compressor da uniformização mundial, aparece uma nova chance para a razão: de prosseguir, a partir da diversidade de culturas, ao que chamarei de « autorreflexão » do humano». Tradução livre do autor.

5.

Intervenção crítica de JeanLoup Amselle no seminário Supports et circulation des savoirs et des Arts (EHESS) em 13/11/2015, sobre a atemporalidade dos objetos do continente africano do novo Museu do Louvre de Abou Dabi. Ler também : SHAEFFER J.-M., 2008, « Le musée du quai Branly entre art et esthétique », Le Débat, $2008 / 1$ (n 148), p. $170-178$.

6.

Ele participou do longa-metragem « Ferman 2010, do Norte ao Sul, do Leste ao Oeste » («Fesman 2010, du Nord au Sud, de l'Est à l'Ouest ») para a terceira edição do Festival Mundial das Artes negras de Dakar em 2010, filme de Christine Douxami e Philippe Degaille. Para ver a versão em português: https://www.canal-u.tv/ video/ehess/fesman_2010_ do_leste_a_oeste_do_ norte_ao_sul.23504 
Mundial das Artes Negras com uma obra em que ele é autor, assistente de direção e um dos atores de « Bloody Niggers » (direção de J. Delcuvellerie, como parte do Groupov). Dorcy Rugamba, nesta obra extremamente política, examina o genocídio de Ruanda à luz dos genocídios que o precederam - todos justificados por uma inferioridade étnica e, portanto, supostamente ontologicamente diferente - e em um segundo momento, questiona a responsabilidade dos africanos nos dias de hoje nos problemas de governo, de conflitos de interesses e, sobretudo, de gestão da diferença. Ele reivindica, com seu falecido amigo senegalês Younouss Diallo, o pan-africanismo como um movimento capaz de superar as tensões identitárias entendidas por eles como anacrônicas e vinculadas a uma exacerbação da diferença entre os diferentes países do continente.

Dorcy Rugamba e Younouss Diallo fundaram escolas de teatro em suas terras natais (na Ruanda e no Senegal) e cada um procura, através dessas estruturas, uma possibilidade de colaborações artísticas para além das fronteiras, que eles consideram artificiais. Pois, como sabemos, os diferentes colonos repartiram os vários territórios colonizados na Conferência de Berlin de $1886^{7}$. As colaborações pan-africanas desses grupos com outras companhias do continente seguem uma após a outra, organizadas a partir de Bruxelas - eles são os « artistas globalizados » formados no Conservatório de Liège - e permitem unir a África do Leste, do Oeste, do Sul. Vivem entre o continente e a Europa. Essas criações clamam por uma tomada de responsabilidade política da parte dos africanos de hoje ${ }^{8}$.

De fato, Dorcy Rugamba é uma figura emblemática do questionamento sobre as artes performativas na África, visto sob o ângulo da reivindicação, ou melhor, da não-reivindicação, da « diferença » frente ao Outro europeu ou africano. Ele se reivindica ao mesmo tempo como um herdeiro da negritude de Léopold Sédar Senghor quem fundou o movimento, mas principalmente de Aimé Césaire, outro fundador, desejando ultrapassá-los. Ele é um mensageiro do pan-africanismo e sobretudo um criador contemporâneo. Ele revela a cena artística de hoje como um reflexo de uma África crítica, em que sutileza de análise de seus atores e a criação de novos paradigmas filosóficos e políticos (RUGAMBA 2014) permitem criar novas redes e novas « fecundidades », retomando-se o termo de François Julien. Ele trabalha ao mesmo tempo com a Uganda, Senegal, Tanzânia e Burkina Faso. Ele levou sua companhia ao festival Les Récréâtrales de Burkina Faso, do qual falaremos mais para frente. Ele se afirma comunista e considera que é preciso se interessar pelas derivas de uma exploração da África por grandes
7 .

A Conferência de Berlin (15 de novembro de 1884 até 26 de fevereiro de 1885) marcou a organização dos países europeus quanto a divisão da Africa entre as grandes potências coloniais da época (Sobretudo Portugal, França, Alemanha, Reino Unido)

8.

Dorcy Rugamba também participou do colóquio organizado em 2012 na EHESS por Christine Douxami e Elena Vezzadini, intitulado "Teatros políticos na África do Norte!” (« Théâtres politiques en Afrique du Nord au Sud ! ». O colóquio está disponível no canal-u, EHESS, www.canal-u.tv/ video/ehess 
empresas e os Estados submetidos à corrupção, para além, segundo ele, de uma reivindicação essencialista. Como afirma o curador da exposição Simon Njami: « O futuro não se aninha na reivindicação excessiva de nossos particularismos, mas na transcendência de si e no encontro com o outro » (PLOUGASTEL 2017).

Além disso, as artes coreográficas, o teatro e a performance na África continuam relativamente desconhecidas e são frequentemente inscritas em um pressuposto primitivista, que podemos denunciar também dentro das artes plásticas (AMSELLE 2010, MALAQUAIS 2012, CELIUS 2015). O teatro na África é frequentemente reduzido ao teatro da intervenção social, herdeiro de Augusto Boal (LE LAY 2014), com frequência instrumentalizado pelas ONGs. Esse teatro de intervenção social é mais conhecido, mas continua à margem de uma criação contemporânea atual, como abordaremos.

Os temas tratados - sobre o tema polêmico de classe-raça principalmente dentro da herança da Negritude de Césaire, mas também a questão de classes, de situações geográficas Norte-Sul e pós-coloniais - pelos autores de teatro contemporâneo africano, especialmente aqueles que questionam a instrumentalização da diferença, são pouco estudados. No entanto, é claro que tanto na África do Norte como na África subsaariana, a cena teatral contemporânea está em verdadeira ebulição e abre um espaço artístico em atrito permanente com a política.

O teatro, mais especificamente a performance, investem em festivais de arte contemporânea, de Johannesburgo a Luanda, e se multiplicam sob formas de caravanas itinerantes, de teatro de rua, ou de espaços alternativos ultra contemporâneos, sem contar os teatros nacionais « clássicos » fundados no momento da independência da maioria dos países africanos. Esses espaços refletem frequentemente as escolhas políticas e um verdadeiro investimento nas questões societárias contemporâneas. Atualmente, trata-se de colocar em perspectiva esses diferentes engajamentos sócio-políticos, de refletir sobre o papel dos autores africanos da diáspora, de suas « idas e vindas » e de tecer as ligações entre diferentes realidades contemporâneas de uma África em movimento.

A renovação do teatro africano pode ser em grande parte atribuída à circulação entre autores, entre festivais, entre diferentes residências de escritura, entre « artistas militantes » do continente. Na realidade, parece que a verdadeira transformação estrutural do teatro vem de iniciativas artísticas locais que, progressivamente, dividem-se em escalas regionais (sub-regiões) e então em escala do continente, ou mesmo do globo. Em cada uma dessas escalas, as redes permitem aos atores se encontrar e se unir, para então obter financiamentos juntos. 
Em Burkina Faso, um festival de teatro como o Récréatrâles, em Ouagadougou, organizado por Etienne Minoungou desde 2002, desenvolve parcerias com os artistas de Ouagadougou, através da associação do Cartel que reúne cinco companhias de teatro (a Compagnie Falinga, o Théâtr' Evasion, o Théâtre Eclair, AGTB e a Compagnie du fil) por uma estrutura de administração e de gestão comum, mas igualmente com os artistas do continente como, por exemplo, o Festival Mantsina sur Scène impulsionado por Dieudonné Niangouna do Congo Brazzaville. Os Récréatrâles apoiaram este festival em sua décima primeira edição, em Brazzaville. As colaborações artísticas sustentam essas parcerias, como com Dieudonné Niangouna, que é o autor do monólogo M’Appelle Mohamed Ali apresentado pelo diretor dos Récréâtrales, Etienne Minougou. O monólogo questiona de maneira bastante contemporânea a figura militante de Mohamed Ali e os desafios do pan-africanismo especialmente dentro de seus aspectos literários e artísticos de hoje.

Dentro dos Récréâtrales, as residências têm espaços para autores, diretores, cenógrafos, atores e fazem « parte de um programa trienal (2014-2015-2016) de pesquisa e de formação em teatro para estimular a emergência de uma incubadora de criadores africanos ${ }^{9}$ através da rede Elan. Em 2014, essa residência reunia artistas de Ruanda, do Senegal, do Mali, da Costa do Marfim, do Níger, entre outras, e em um espírito pan-africano. Um outro festival, desta vez de arte de rua, intitulado Rendez vous chez nous, criado em 2009 em Burkina, trabalha nesse mesmo espírito e reúne companhias de toda a sub-região com, em 2015, artistas do Benin, da Costa do Marfim, de Gana, do Mali, do Chade, de Togo e do Niger. Além disso, como explica o site do festival, o desafio é de profissionalizar as artes da rua através do seminário de formação. Em 2015, o encontro « Structuration et développement des arts de la rue » realizado em três dias permitiu informar doze diretores de companhias e/ou de festivais da África ocidental ${ }^{10}$. Neste mesmo período a reunião UNIMA - União Internacional de Marionete foi realizada durante uma semana entre quatorze profissionais de marionetes do oeste africano. Esses dois encontros oferecem perspectivas verdadeiras sobre a rede de parcerias e a visibilidade de atores culturais da sub-região, no contexto da estruturação da economia do espetáculo ao vivo e das artes de rua.

No nível local da capital burquinabê, « o Cartel » além do reagrupamento estratégico visando a reduzir as tarefas administrativas e de gestão de companhias, o Cartel, através da sua « temporada teatral » que difunde as criações de suas cinco companhias visa a desenvolver e a pôr em prática um teatro cidadão que o site assim define: «Il s'agit de mettre en place des initiatives de création
9.

Site do Festival Récréâtrales (consultado no dia 20/og/2017) http://www. recreatrales.org/fr/

10. Rencontre animée en 2015 par Daniel Andrieu, fondateur des Ateliers 231 et directeur du Festival Viva Cité à Sotteville-Les-Rouen et Claudine Dussolier éditrice et présidente du CNAR Le Moulin Fondu. 
de qualité, mais qui ne soient pas coupées de leur public naturel. Trop souvent, les créations de théâtre « à texte » se déploient dans le cadre de coproductions avec des pays du Nord, et dans le but d'être présentées avant tout à un public du Nord. Pourtant, les expériences menées ces dernières années montrent que le théâtre d'auteur peut aussi être le support d'une démarche artistique subtile, et que le public populaire apprécie les productions de qualité si elles sont montées avec des exigences professionnelles et de respect de son auditoire. La création théâtrale peut ainsi constituer un véritable instrument de renforcement de la citoyenneté, en suscitant la réflexion, mais aussi en apportant au public le plaisir de la rencontre avec une véritable oeuvre d'art $\gg^{11} 12$.

Essa ambição de reconectar o teatro de autor com o público popular via o desenvolvimento de um teatro cidadão ilustra a força de ideias criativas que pode impulsionar a rede de companhias. Pois se sua união favorece as parcerias artísticas, ela pode também suscitar mensagens políticas sólidas. Além de seu projeto artístico, o Cartel alimenta o projeto de uma « Coalizão africana para a Cultura ». Partindo do fato que esta reflexão se faz geralmente fora da Africa, o que gera uma « descentralização » recorrente da reflexão sobre a cultura na África (uma reflexão produzida fora, financiada no exterior e fundada sobre o olhar do outro) que leva a reduções de autonomia criativa, eles desejam iniciar uma reflexão sobre a cultura na África que possa inspirar novas políticas em nível local, regional e continental. A ideia é, portanto, de se libertar de uma visão da cultura eurocêntrica imposta pelos financiamentos do Norte. Nessa reflexão, o desenvolvimento reduziria a cultura a « um truque, integrado a estratégia das ONGs e de cooperações internacionais que a vejam como uma forma de alcançar o desenvolvimento humano sustentável ».

Esse último ponto, acerca das colaborações com ONGs, é uma crítica direta a um certo tipo de teatro ligado a ideia do desenvolvimento que existe na África desde os anos 1970. De fato, o Teatro do Oprimido, fundado pelo brasileiro Augusto Boal durante os anos 1970, retomado por seu coligado « Teatro Ação », os dois muito presentes na África, ofereceram verdadeiras perspectivas econômicas aos atores e diretores africanos. A Coalizão africana para a cultura denuncia os riscos assumidos em termos artísticos por esse teatro que peca pela falta de poesia e de criatividade, por ser muito impregnado pela causa que defende e que lhe seria « ditado » por seus financiadores ocidentais (luta contra a aids, conscientização sobre a circuncisão feminina, as relações homem-mulher, por exemplo).
11.

http://www.lecartel.net/

la-federation

12.

« Trata-se de implementar iniciativas de criação de qualidade, mas que não sejam separadas de seu público natural. Muito frequentemente, as criações de teatro «texto» são implementadas em coproduções com países do Norte, com o objetivo de serem apresentadas antes de tudo para o público do Norte. Contudo, as experiências conduzidas nos últimos anos mostram que o teatro de autor também pode ser o suporte de uma abordagem artística sutil e que o público popular aprecia as produções de qualidade se elas são montadas com exigências profissionais e de respeito do seu público. A criação teatral pode assim constituir um verdadeiro instrumento de fortalecimento

da cidadania, levantando a reflexão, mas também levando ao público o prazer do encontro com uma verdadeira obra de arte. » Tradução livre do autor. 
Esse teatro permitiu colaborações entre ONGs e companhias teatrais e constitui, até os dias de hoje, as fontes de renda principais para algumas dessas companhias. Esse teatro colabora também com canais de televisão, que lhes solicitam para programas de « teatro filmado » sobre temas ligados a questões de desenvolvimento.

Além disso, a televisão os solicita para emissões humorísticas, para as quais eles utilizam praticamente o mesmo tipo de jogo que para o Teatro do Oprimido. Trata-se de uma verdadeira economia paralela para essas companhias ${ }^{13}$. Citemos, a título de exemplo, a companhia do falecido Jean Pierre Guingané, O Teatro da Fraternidade, que divide seu trabalho entre peças do Teatro Ação, que a companhia domina em várias línguas praticadas na Burkina Faso a fim de apresentar em todo o território burquinabê, patrocinado por ONGs ou ministérios burquinabês, e peças de « criação » que ela apresenta mais esporadicamente. O Cartel e a Coalizão para a cultura reivindicam um teatro de criação, de autor, não a serviço do « desenvolvimento », compreendido como ligado diretamente aos países do Norte como seus colegas do teatro-ação, mas a serviço de uma Arte do Sul voltada a seus públicos locais.

Essa arte não mostraria mais uma África minada por problemas sociais, mas uma África criadora e criativa. Etienne Minoungou afirma que:

"Ce sont alors les partenaires internationaux de coopération qui, d'autre part, ont choisi d'analyser et d'approcher les productions culturelles africaines comme «outils de développement». Face à un continent estimé en retard sur la marche du monde, les démarches de création ont été, souvent à juste titre, considérées comme autant de vecteurs possibles du changement social. Il a été demandé à l'homme de théâtre, au cinéaste, au chanteur et parfois à l'écrivain de sensibiliser les populations à la nécessité de scolariser les fillettes, de mettre fin à l'excision ou de se prémunir contre la progression du Sida. La sensibilité du créateur, l'urgence de son message et la puissance de l'oeuvre qui lui permet de transmettre ce message aux hommes individuellement et au monde en général se sont effacées devant les exigences d'une efficacité dans la diffusion d'un message standardisé (immédiatement accessible), voire commandité de l'extérieur 》 ${ }^{14} 15$.

Além disso, quando as razões para acreditar na cultura da África são evocadas, o termo desenvolvimento é evadido em função dos «futuros coletivos ». Além dos quadros locais e nacionais, « la Coalition africaine pour la culture vise à réunir, au niveau régional, voire continental, les arguments et les énergies sus-
13.

Sobre as ligações de teatro-ONG na África Central, ver a obra de Le Lay Maëline, "La parole construit le pays". Théâtre, langues et didactisme au Katanga (República Democrática do Congo), Paris, Honoré Champion, coll. Francophonies, 2014, 496 p.

14.

http://www.africultures.com/ php/?nav=article\&no $=8542 \#$ thash.usLzJ3Rz.dpuf, consultado dia 22.9.2015.

15

«Foram então os parceiros de cooperação internacional que, por outro lado, optaram por analisar e abordar as produções culturais africanas como « ferramentas de desenvolvimento ». Frente a um continente considerado atrasado em relação ao mundo, as iniciativas de criação foram, muitas vezes com razão, consideradas como possíveis vetores de mudança social. Foi requisitado ao homem do teatro, ao cineasta, ao cantor e às vezes ao escritor sensibilizar as populações sobre a necessidade de escolarizar as meninas, de acabar com a circuncisão ou de se proteger contra a progressão da Aids. A sensibilidade do criador, a urgência de sua mensagem e o poder da obra que lhe permite transmitir essa mensagem aos homens individualmente e ao mundo em geral foram apagadas diante das exigências da eficácia da difusão de uma mensagem padronizada (imediatamente acessível), ou mesmo encomendada do exterior. Tradução livre do autor. 
ceptibles de constituer un instrument de lobbying et d'alerte auprès des organisations régionales, sous-régionales et panafricaines, dans le but d'obtenir la mise en oeuvre de politiques d'appui financiers au secteurculturel ». ${ }^{1617} \mathrm{~A}$ Coalizão reivindica, portanto, umespírito pan-africanista, partindo do princípio que o continente possui uma forte consciência de identidade e de um destino comum, e que ele está ausente dos grandes debates mundiais sobre a cultura, enquanto poderia constituir uma fonte de ideias criativas de um outro discurso.

Esse espírito pan-africanista, se for a base de um projeto ainda teórico, encontra-se na realidade na rede e na profissionalização possibilitada através de trocas entre companhias. Assim, o Centro de Desenvolvimento Coreográfico La Termitière (C.D.C.) de Ouagadougou, criado em 2004 em Burkina Faso, colabora com os parceiros do continente, como os quenianos do Gaara Project ou os senegaleses da École des Sables de Germaine Acogny, mesmo se o Institut Français das filiais de Burkina e de Paris continue sendo o principal parceiro. As parcerias artísticas conduzem também a novas parcerias financeiras: o programa Chrysalides é o fruto de uma colaboração entre a Termitière, a École des Sables e o Gaara Project, com três períodos de trabalho em cada país e 20 companhias do continente, com o apoio da Comunidade Europeia e a ACP Culture, como parte de um « programa de ações de cooperação e de desenvolvimento das artes coreográficas na África » 18. O projeto da Termitière, « eu danço logo eu sou », associou artistas do centro coreográfico a dançarinos malianos.

Os empréstimos e as trocas entre artistas pan-africanos incluem artistas ditos da « diáspora » Norte e Sul-americanos. Por exemplo, o projeto senegalês de valorização das artes e do digital Kër Thiossane desenvolveu colaborações tanto com a África do Sul como o Haiti. Do mesmo modo, na área da dança, Germaine Akoni da École des Sables, herdeira do pensamento senghoriano e instigadora de uma « Dança Africana » (termo polêmico como explica a pesquisadora Mahalia Lassibille), solicitou amplamente a colaboração de artistas brasileiros e abriu seus estágios na École des Sables, em uma perspectiva pan-africana, aos artistas da diáspora do Norte e Sul-americanos. Assim os artistas militantes da causa «afro» como Carmen Luz, da Companhia Etnica do Rio de Janeiro, colaboraram com a École des Sables. Carmen Luz conseguiu criar novas redes artísticas com a África, graças as quais ela visita regularmente festivais de teatro onde ela pode integrar residências artísticas Fitheb do Benin e Mindelact do Cabo Verde - como ela fez com companhias de dança contemporânea do Mali (GnagamiX) e
16.

http://www.africultures.com/php/?nav=article\&no=8542\#sthash.usLzJ3Rz.dpuf, consultado dia 22.9.2015 17. « a Coalizão africana para a cultura visa reunir, em nível regional, e até mesmo continental, os argumentos e as energias que poderiam constituir um instrumento de lobby e de alerta para as organizações regionais, sub-regionais e pan-africanas, com o objetivo de obter a implementação de políticas de apoio no setor cultural ». Tradução livre do autor.

18.

Site da Termitière consultado dia 10.9.2015. http://www. cdc-latermitiere.org/index. php?option=com_content\&view=article\&id=63\&Itemid $=67 \&-$ $390 c d j b d c 34 f c 9 b 84 a 00 e f 3 b 5 c 1 b 6 a f-$ $d=8847$ f45c4cea035f3dga0283fofdc83f. O Eeg Cowles Foundation de Chicago, associação de artistas e pesquisadores norte-americanos, visa a uma colaboração em relação à pesquisa e a criação em artes do espetáculo e apoia a Termitière. Outras associações com fins não lucrativos apoiam os eventos da Termitière, como a AAD (African Artists for development), que considera o trabalho artístico como ponto de partida para o desenvolvimento, mas dentro do qual o papel exato dos artistas ainda é pouco definido (http://aad-fund.org/artistes/ ) e mantém uma visão de "assistência" mesmo se o site procure se defender. Um mesmo evento (a $11^{\mathrm{a}}$ edição do Festival Diálogo de Corpos) pode ser apoiado por um parceiro financeiro "do Norte" como a AAD, mas também pela Embaixada da Costa do Marfim ou pela UEMOA (União Econômica e Monetária do Oeste Africano). De fato, esses espaços de desenvolvimento da arte coreográfica pertencem a um mundo contemporâneo da criação em um mundo globalizado e isso é particularmente forte para a dança contemporânea, como mostrou a pesquisadora Sarah Andrieu, mas igualmente para as artes plásticas e as artes cênicas. Mas parece que a verdadeira transformação estrutural vem do fato que o ponto de partida vem de uma iniciativa artística local, em seguida regional (sub-região), continental, e então em escala do globo, mas partindo de um ato de criação artística. Então, a partir dessas colaborações, os artistas se unem e obtêm financiamentos. 
de Burkina Faso ${ }^{19}$. As colaborações de atores culturais brasileiros com a África, que podem ser encontrados em diferentes campos, podem ir além das expressões artísticas para contribuir no debate pan-africanista sobre a cultura e participar da construção de novas políticas culturais, sendo as do Brasil originais em seu relacionamento com o desenvolvimento.

\section{A Unidade, a diferença, a conformidade ou}

o bem comum através da pesquisa-ação e da pesquisa-criação?

Mas como estudar essas manifestações cênicas contemporâneas enquanto artista-pesquisador? Além disso, como não entrar em uma redução pela Diferença, quer se trate da cor da pele ou de uma Diferença ligada à uma deficiência? Essa pesquisa sobre a Diferença pode ser aprofundada pelo viés de uma pesquisa-ação ou, mais exatamente, de uma pesquisa-criação. A pesquisa-ação desde seu auge nos anos 1970 sofreu algumas incertezas, mas continua válida para compreender a necessidade de uma participação do pesquisador em seu tema de estudo. Isso vale também para o artista-pesquisador: tratando-se de arte, parece lógico se « engajar » fisicamente nessa empreiteira artística.

A postura passiva do etnógrafo-observador exaltado por Malinowski parece criticável, mesmo se esta posição tenha sido saudavelmente desenvolvida em resposta a um abuso de intervencionismo, este último tendo sido legitimado pelo conceito etnocêntrico de superioridade cultural no momento do colonialismo. No entanto, a não-reação que valoriza o relativismo cultural e o particularismo, às vezes, leva à exclusão do Outro. O risco é muitas vezes de negar a humanidade do Outro, considerando-o apenas como « diferente ». É esta armadilha que nós desejamos evitar colocando-nos desde o princípio como « diferentes » pelas nossas origens, nossas práticas artísticas, mas também nossas formas de apreender o mundo de uma maneira sensível. Ao trabalhar o « Diferente » a partir de uma outra forma de sentir o mundo, como aquele do deficiente, nós procuramos evitar ao mesmo tempo a estigmatização do portador de deficiência, como também de toda pessoa diferente, quer seja de uma diferença da cor da pele, de gênero, de etnia ou de sexualidade.

Jean Loup Amselle (1990, p.10) em uma crítica do relativismo cultural escreveu: «Tout anthropologue ayant une réelle expérience de terrain sait que la culture qu'il observe se dissout dans un ensemble sériel ou dans un réservoir de pratiques conflictuelles ou pacifiques dont les acteurs sociaux se servent pour renégocier en permanence leur identité. Figer ces pratiques aboutit à une vision essentialiste de la culture qui à la limite est une forme moderne de racisme ». ${ }^{20}$
19.

Para o Fitheb, Carmen Luz criou um espetáculo de dança: DOIS IRMÃOS resultado da residência de criação. Para o Mindelact, ela criou uma performance de rua que é principalmente dançada (sem título). Para a Cie Gnagamix, o resultado de sua residência se chama: SEM TÍTULO - Primeiros Rascunhos Coreográficos para Dolo.
20.

Todo antropólogo tendo uma experiência real de campo sabe que a cultura que ele observa se dissolve em série ou em um reservatório de práticas conflitantes ou pacíficas, das quais os atores sociais se servem para renegociar permanentemente sua identidade. Congelar essas práticas leva a uma visão essencialista da cultura, que é uma forma moderna de racismo. Tradução livre do autor. 
Como destaca Devereux (1980, p. 225): «A pesquisa do que é único praticamente induz alguns analistas do comportamento a negar a unidade psíquica da humanidade e a atribuir uma 'psicologia especial' a cada grupo étnico ». Devereux condena, aliás, os excessos de neutralidade do pesquisador: «O relativismo cultural que concebe a humanidade como um 'museu de costumes' reconhece a existência de seres humanos, mas, em nome da objetividade científica, recusa-se a aplicar as normas étnicas comuns a seu comportamento » (p.133). Ele dá o exemplo de um etnólogo que não teve reação quando uma pessoa havia sido enterrada viva e «perdeu sua alma » e que, quando ele foi interrogado sobre seu comportamento teria respondido: « Enquanto etnólogo, eu não devo supor os costumes do país, mas estudá-los ». Para Devereux, trata-se neste caso de uma negação obsessiva da legitimidade do julgamento étnico. Ele cita sua própria prática quando, condenando certas práticas que ele julgava repreensíveis entre os Sedang, ele descobriu qual era seu real significado na comunidade.

Consequentemente, o etnólogo, graças a numerosos trabalhos de campo, pode, ao final, adotar uma postura dialógica e sugestiva dentro desta sociedade. Essa atitude, que eu chamaria de « participação-ação », não é nova na antropologia. Ela foi o resultado de casos isolados no início da disciplina antropológica, e depois se desenvolveu particularmente nos anos 1970, com um recuo acentuado desde os anos $1980^{21}$. Roger Bastide se inclinou sobre o caso da « antropologia aplicada » em uma obra publicada em 1971; Jean Copan, mais radical em seu trabalho, chamou, em 1975, de uma luta contra o imperialismo e valorizou o pesquisador-militante, « o antropólogo revolucionário » que contribuiria para construir uma «antropologia da libertação ${ }^{22}$. Michel Agier (1997 p.21) estima que esse tipo de perspectiva às vezes experimentou um deslize « populista » e levou o pesquisador a perder a distância crítica.

A etnóloga Jeanne Favret-Saada qualifica esse tipo de etnografia de «observador engajado». Ela reivindica essa atitude: « de tous les pièges qui menacent notre travail (d'anthropologue), il en est deux dont nous avions appris à nous méfier, comme de la peste : accepter de "participer" au discours indigène [critiquant justement la « recherche-action »], succomber aux tentations de la subjectivité. Non seulement il m'a été impossible de les éviter, mais c'est par leur moyen que j'ai élaboré l'essentiel de mon ethnographie » ${ }^{23} 24$.

Para nós, esse tipo de postura permite uma troca, em termos dialógicos, de saberes respectivos da antropologia, da comunidade estudada e mais largamente de suas expressões artísticas. Participar é antes de tudo retribuir simbolicamente as chaves
21.

A sociologia na América Latina desenvolveu bastante o conceito da "pesquisa-ação" nos anos 1970 e 1980. Para o Brasil, considera-se a obra de THIOLLENT Michel, Metodologia da pesquisa-ação, Cortez Editora, São Paulo, 1996, Je ed. e a de BRANDÃO C. R. (org.), Repensando a pesquisa participante, Brasiliense, 1984, assim como a terceira parte do livro de FROTA HAGUETTE Teresa Maria, Metodologias qualitativas na sociologia, ed. Vozes, Petropolis, 1987.

22.

Ler sobre esse assunto : BASTIDE Roger,

L'anthropologie appliquée, Flammarion, Paris, 1971 e COPANS Jean, Anthropologie et impérialisme, Maspero, Paris, 1975.

23.

FAVRET-SAADA Jeanne, Les mots, la mort, les sorts, Gallimard Folio Essais, Paris, 1994, p. 48. citado por François Laplantine em La Description ethnographique, op. cit., p. 120.

24.

« de todas as armadilhas que ameaçam nosso trabalho (de antropólogo), há duas que nós teríamos aprendido a desconfiar, como da peste: aceitar « participar » do discurso indígena (criticando justamente a « pesquisa-ação ») e sucumbir às tentações da subjetividade. Não apenas me foi impossível de os evitar, mas foi pelos seus meios que eu elaborei o essencial da minha etnografia ». Tradução livre do autor. 
da compreensão da sociedade que lhe são fornecidas pelos seus interlocutores. Em suma, essa postura de etnólogo é certamente uma atitude militante e não-obrigatória, mas não suscetível de ser reprimida desde que respondendo a troca pela troca, quando for possível e adequado. Michel Agier (1997) chamaria esta atitude do pesquisador moderno de « engajamento fundamentado » onde o antropólogo está presente e responde às demandas e às solicitações « evitando as três armadilhas cumulativas do elitismo, do populismo e do corporativismo » (p. 24), este último gerando um declínio em si mesmo.

Entretanto, esse tipo de participação pode gerar numerosos desvios, dentro dos quais os antropólogos arrogaram o direito de falar e de decidir « em nome » da comunidade. É, portanto, necessário ter um olhar extremamente crítico sobre si mesmo durante sua participação para saber respeitar os limites entre si e o Outro, entre a compreensão do Outro e sua « apropriação », mesmo se esta atitude participativa e compreensiva parte de uma « boa intenção ». Como explica Georges Devereux: « As deformações etnocêntricas características, devido à cultura a qual ela pertence, são inevitáveis. Mais que lamentar nós devemos levar isso em conta » (p. 198). É preciso, portanto, permanecer consciente de sua existência principalmente no momento da participação. Como explica Jean Pierre DOZON (1997), o antropólogo, principalmente se for comprometido, deve ser vigilante e « desenvolver um movimento de autorreflexão, tornando-se literalmente seu próprio objeto de estudo » (p. 117).

Enquanto artista, para conduzir uma criação em colaboração com outros artistas vindos de uma outra cultura, é preciso ser vigilante: face ao respeito do grupo de artistas culturalmente diferente, ou face aos deficientes saídos de uma outra cultura, culturalmente, mentalmente e corporalmente diferentes e se considerar artista-pesquisador necessariamente em estado de observação de uma cultura diferente e como afirma G. Devereux, será preciso ter em conta «as deformações etnocêntricas características» para se desviar e as tornar artisticamente matéria para criação.

A partir dessas precauções metodológicas, torna-se possível considerar uma pesquisa-criação, durante a pesquisa-ação quando se estuda arte. De fato, envolver-se com artistas dentro de uma lógica da antropologia participante é necessariamente participar artisticamente. Assim, a autora deste artigo, pode interpretar recentemente Anjo Negro, de Nelson Rodrigues (em 2014 no Rio de Janeiro e em 2015 na França), em que ela fez o papel do médico negro e não a mulher branca, graças à uma pesquisa-criação que a permitiu ao mesmo tempo a participação e a inversão teórica 
dos papeis. Mesmo para pesquisas sobre o teatro negro no Brasil, ela participou como atriz em trupes afro-brasileiras para fazer os papeis do Outro (DOUXAMI 2015).

Esses ateliês são feitos em uma perspectiva ao mesmo tempo da « arte relacional » (que exalta a relação com o Outro sem o artifício de poder) em ligação com aquela promovida por Paul Helguera (2011) a socially engaged art, que " pressupõe uma dimensão ativista e artística de projetos que desfocam as fronteiras entre projeto social e artístico, buscando como podem ser otimizadas as relações entre uma comunidade específica e um artista ou um coletivo de artistas. Nesse sentido, são criados espaços utópicos, regidos por valores de cooperação, de solidariedade, de encontro, de potencialização dos afetos » (ALICE, 2015, p. 398). Como afirma Tania Alice, não se trata de uma arte espetacular, mas da implementação que permite àquele que olha não ser excluído da performance, mas de ser convidado a fazer parte dela emocionalmente e fisicamente. Ela evoca uma performance curativa, ao mesmo tempo arte e cura para o artista e para aquele que a encontra. Não se trata, segundo Tania Alice, de considerar a parte frágil do indivíduo, mas sim sua parte válida; esta última, uma vez estimulada pela atividade artística, acabará por invadir a primeira para além da norma e da normalidade, dando-lhe um novo vigor. A partir do material colhido, às vezes performativo, textual ou emocional, os artistas podem imaginar uma performance.

De fato, a questão da diferença tanto cultural como física aparece cruamente para nós. Em nossa utopia artística, procuramos colocar o ser « Diferente » no centro e o « Mesmo » às margens, em uma vontade de bem comum, coletivo. Segundo JAMESON (2007, p.61) « A utopia é uma operação que visa revelar os limites da nossa própria imaginação do futuro, as linhas que nós não parecemos capazes de atravessar imaginando as mudanças na nossa vida e nosso mundo ». Igualmente, em termos de pesquisa, a arte política performativa do continente africano, principalmente no que se refere à afirmação de uma diferença a partir movimento da Negritude, pode ser considerada como não-periférica. Mais ainda, a arte performativa contemporânea no contexto da África pode ser posta no centro, com o mesmo título e a mesma legitimidade artística daquela encontrada na Europa. O movimento atual de reabilitação das artes plásticas africanas (desde Africa Remix principalmente) conhece pouco a pouco seu equivalente nas artes performáticas. A renovação atual do teatro contemporâneo, assim como a da dança, passa pela inclusão dessas « novas » dramaturgias. 


\section{REFERENNCIAS}

ALICE Tania. PARC: Performance de Arte Relacional como Cura. Revista Brasileira de Estudos da Presença (UFRGS), Porto Alegre, vol. 5, n. 2, 2015. pp. 396-412.

AGIER Michel (dir.). Introduction. In: Anthropologues en dangers: l'engagement sur le terrain. Paris: Jean Michel Place, 1997.

AMSELLE Jean Loup. Logiques métisses: anthropologie de l'identité en Afrique et ailleurs. Paris: Payot, 1990.

AMSELLE J.L., 2005. L'art de la friche, essai sur l'art africain contemporain. Paris : Éd. Flammarion, 2005, 214 p.

AMSELLE J.L. Rétrovolutions: Essai sur les primitivismes contemporains. Paris: Stock, 2010, 232 p.

ARDENNE, Paul. Un Art Contextuel: création artistique en milieu urbain, en situation d'intervention, de participation. Paris: Flammarion, 2004.

BISHOP, Claire, Artificial Hells: participatory art and the politics of spectatorship. New York :Verso, 2012.

BLIN Myriam Odile. Arts et cultures d'Afrique en recherche: vers une anthropologie solidaire, PURH, Presses Universitaires de Rouen et du Havre, 2012, Arts dans la mondialisation.

CELIUS C. A., 2015. Quelques aspects de la nouvelle scène artistique d'Haïti. Gradhiva 1/2015 (n²1), Paris, pp. 104-129CELIUS C. A, 2005. Cheminement anthropologique en Haïti. Gradhiva 1/2005, Paris, pp. 47-55.

COLLEYN J.P., DEVILLEZ F. Le tourisme et les images exotiques. Cahiers d'études africaines, 193-194 (1-2), 2009, pp. 583-594.

DEVEREUX Georges. De l'angoisse à la méthode dans les sciences du comportement. Paris: Aubier, 1980.

DOUXAMI C. Le Théâtre Noir Brésilien, un processus militant d'affirmation de l'identité afro-brésilienne. Collection Sociologie de l'Art, L'Harmattan, Paris, 2015, 322 p. DOUXAMIC. etDEGAILLE Ph.intituléFESMAN2010,duNordauSud, del'Estàl'Ouest, CEAF-Captures Production, HD, 107mn, 2012. Voir pour la version portugaise:https:/www.canal-u.tv/video/ehess/ fesman_2010_do_leste_a_oeste_do_norte_ao_sul.23504 DOQUET A., Se montrer dogon. Les mises en scène de l'identité ethnique. Ethnologies comparées, online, 2002, n ${ }^{\circ} 5$.

DOZON J.P., Conclusions. In: AGIER Michel (org.). Anthropologues en dangers: l'engagement sur le terrain, Jean Michel Place, Paris, 1997.

FIQUET E. VINCENT Cédric. Résonances et oublis des festivals fondateurs des scènes artistiques africaines postcoloniales. In : BLIN, Myriam Odile. Arts et cultures d'Afrique en recherche: vers une 
anthropologie solidaire, PURH, Presses Universitaires de Rouen et du Havre, 2012, Arts dans la mondialisation.

FIQUET E., GALLIMARDET Lauraine. On ne peut nier longtemps l'art nègre. Enjeux du colloque et de l'exposition du Premier Festival mondial des arts nègres de Dakar en 1966. Gradhiva, nº ${ }^{\circ}$, Présence africaine. Les conditions noires: une généalogie des discours, 2009. JACKSON Shannon. Social Works: performing arts, supporting publics. New York, Routledge, 2011.

JAMESON F. l'utopie comme méthode. Contre Temps, n²0, 2007. JULIEN François. Le Pont des singes (De la diversité à venir). Fécondité culturelle face à identité nationale, Galilée, 2010.

JULIEN François. L'écart et l'entre. Leçon inaugurale de la Chaire sur l'altérité. Galilée, 2012.

HELGUERA P. Education for a socially engaged art. New York, NY: Jorge Pinto Books, 2011.

KESTNER Grant, The One and the Many: contemporary collaborative art in a global context. Durham: Duke University Press Book, 2011.

LACHAUD J.M. Que peut (malgré tout) l'Art ? L'harmattan, col. Ouverture philosophique, $162 \mathrm{p}$.

LE LAY M., La parole construit le pays. Théâtre, langues et didactisme au Katanga (République Démocratique du Congo), Paris, Honoré Champion, 2014, 496 p.

LE LAY M., D. MALAQUAIS D. , SIEGERT N., Archive (re)mix. Vues d'Afrique, Presse Universitaire de Rennes, Rennes, 2015.

LEMOINE Stéphanie, OUARDI, Samira. Artivisme: art, action politique et résistance culturelle, Paris: Alternatives, 2010.

MALAQUAIS Dominique. Hervé Yamguen, Hervé Youmbi, ou les masques rebelles. In Myriam Odile Blin. Arts et cultures d'Afrique en recherche: vers une anthropologie solidaire, PURH, Presses Universitaires de Rouen et du Havre, 2012, Arts dans la mondialisation. MALAQUAIS Dominique. Sparck. De(s)générations, 15, Postérité du Postcolonial, 2012.

RUGAMBA Dorcy. In Po\&sie. Afriques 2, numero 157-158, Ed. Belin, 2017.

RUGAMBA Dorcy. Les problèmes éthiques que soulève l'esthétique d'EXHIBITB, 2012, partiellement dans Rue 89. In: https://dorcyrugamba.wordpress.com/2014/12/28/les-problemes-ethiquesque-souleve-lesthetique-d-exihibit-b/

SHAEFFER J.-M., 2008. Le musée du quai Branly entre art et esthétique. Le Débat, 2008/1 ( $n^{\circ} 148$ ), p. 170-178.

THOMPSON Nato. Living as Form: socially engaged art from 1991 to 2012. Cambridge: MIT Press, 2012. 